\title{
Reassessing Luck Egalitarianism
}

\author{
Nicholas Barry The University of Western Australia
}

\begin{abstract}
In this paper, I analyze two major problems with brute luck egalitarianism. The first problem is that some instances of option luck inequality are inconsistent with the underlying motivation of the luck egalitarian project, and the second problem is that brute luck egalitarianism, at least on Dworkin's formulation, is insufficiently sensitive to the way background inequalities shape individual choices. Whilst G.A Cohen's more nuanced version of brute luck egalitarianism overcomes the second problem by focusing on the genuineness of choices, it does not avoid the first problem of noncompensable option luck. I outline a revised theory of luck egalitarianism that overcomes both problems by focusing on the extent to which individuals have genuinely chosen the level of well-being they enjoy, rejecting the distinction between noncompensable option luck and compensable brute luck. I conclude by outlining the radical redistributive implications of this theory, which run counter to the direction of recent left-liberal policy "modernization."
\end{abstract}

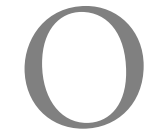
ver the last 15 years, the notion of individual responsibility has played an increasingly important role in left-liberal politics. Politicians such as former U.S. President Bill Clinton, and former British Prime Minister Tony Blair, have enjoyed electoral success after "modernizing" the liberal/social democratic political program, placing greater emphasis on individual responsibility. This development is not surprising because appeals to responsibility resonate strongly with the electorate, as the success of the New Right demonstrates (see Scheffler 2001, 3, 22-26). But according to critics, traditional left-liberal policies undermine individual responsibility, so it is no surprise that politicians have sought to "modernize" by tightening the eligibility criteria for welfare payments, emphasizing the importance of lower tax rates, and generally distancing themselves from "old-style" redistributive politics.

Recent work in normative theory has reflected these developments. Some critics have argued that the notion of individual responsibility plays little role in contemporary left-liberal political theory, linking this to the decline of the traditional left-liberal political program (e.g., Scheffler 2001, 12-31). ${ }^{1}$ Other leftliberal theorists have responded by developing an approach to egalitarian justice that shifts the notion of individual responsibility to center stage. This approach has been termed "luck egalitarianism" because it aims to neutralize the impact of luck on the lives of individuals. ${ }^{2}$ However, luck egalitarians are only concerned with correcting the effects of brute luck, which is unchosen, whilst the effects of option luck, which arises from deliberate gambles, are allowed to stand. The purpose of this distinction is to hold individuals responsible for the consequences of their choices.

In this paper, I will reassess luck egalitarianism, which has come to dominate left-liberal debate over egalitarian justice. Whilst supporting the idea that egalitarianism should be sensitive to notions of choice, luck, and responsibility, I challenge the option luck-brute luck distinction, which lies at the heart of

\footnotetext{
${ }^{1}$ More precisely, Scheffler (2001, especially 16-21) argues that the "traditional" conception of individual responsibility, which is based on the idea of preinstitutional desert, plays little role in contemporary philosophical liberalism. Instead, "the prevailing liberal orthodoxy in philosophy" (18) is to adopt an institutional notion of responsibility, where our desert simply reflects whatever institutional arrangements regarding distribution are in place. In contrast, a preinstitutional notion of desert helps determine what distributive justice is, and thus what these institutional arrangements should be.

${ }^{2}$ The term "luck egalitarianism" was first used in Anderson (1999) and has been discussed in subsequent publications, including Arneson (2000), Callinicos (2000), Dworkin (2002, 2003), Kaufman (2004), Knight (2005, 2006), Ramsay (2004), Scheffler (2003a, 2003b, 2005); Segall (2005, 2007), Vallentyne (2002) and Voigt (2007). See also a 1999 BEARS online symposium on Anderson's article at <http://www.brown.edu/Departments/Philosophy/bears $>$. Dworkin is generally regarded as the founder of luck egalitarianism, although he objects to being described as a "luck egalitarian" (Dworkin 2003).
}

The Journal of Politics, Vol. 70, No. 1, January 2008, Pp. 136-150

doi:10.1017/S0022381607080103 
current theories of luck egalitarianism. ${ }^{3}$ In the first section, I question whether we have a basis for distinguishing between compensable brute luck and noncompensable option luck, suggesting that some instances of option luck inequality may be unjust. In the second section, I develop a second criticism, suggesting that the option-brute distinction has inegalitarian implications because it is insensitive to the way background inequalities shape the different choices that individuals make. Although Ronald Dworkin, who first developed the concepts of option luck and brute luck, put egalitarian conditions on the circumstances in which individual choices can lead to legitimate inequalities, his conditions are insufficient. In the third section, I analyze whether G.A. Cohen's alternative interpretation of brute luck egalitarianism can escape these problems. Whilst Cohen's focus on the genuineness of our choices renders brute luck egalitarianism sensitive to the impact of background inequalities on individual choices, his approach is still vulnerable to the objection highlighted in section 1 because he regards option luck as noncompensable. I propose in the fourth section a revised form of luck egalitarianism that moves beyond option luck and brute luck, focusing instead on the extent to which individuals have genuinely chosen outcomes. This approach overcomes the two objections discussed in the paper, and provides a way of coherently incorporating a notion of individual responsibility into egalitarian theory. I conclude by highlighting the radical redistributive implications of this proposal, which run counter to the kind of liberal and social democratic policy "modernization" we see today.

\section{Compensable Option Luck}

Dworkin developed the distinction between option luck and brute luck to help egalitarians handle the problem that emerges as an initially equal distribution of social resources is disrupted over time by various events and actions. When deviations from the original distribution reflect brute luck, they are unjust and should be corrected, whilst those arising from option luck are just and noncompensable

\footnotetext{
${ }^{3}$ Because these theories equalize brute luck, not option luck, I will generally refer to them as theories of "brute luck egalitarianism" in the rest of the paper. This will also help to distinguish these orthodox forms of luck egalitarianism from the revised theory I outline later that rejects the option-brute distinction. The term "brute luck egalitarianism" is from Vallentyne (2002, 540 n. 17).
}

because they reflect individual choice. Dworkin explains the two concepts as follows:

Option luck is a matter of how deliberate and calculated gambles turn out-whether someone gains or loses through accepting an isolated risk he or she should have anticipated and might have declined. Brute luck is a matter of how risks fall out that are not in that sense deliberate gambles. If I buy a stock on the exchange that rises, then my option luck is good. If I am hit by a falling meteorite whose course could not have been predicted, then my bad luck is brute (even though I could have moved just before it struck if I had had any reason to know where it would strike). Obviously the difference between these two forms of luck can be represented as a matter of degree, and we may be uncertain how to describe a particular piece of bad luck. (Dworkin 2000, 73)

This distinction means that egalitarians can both support equality and hold individuals responsible for their choices. In this way, "Dworkin has, in effect, performed for egalitarianism the considerable service of incorporating within it the most powerful idea in the arsenal of the anti-egalitarian right: the idea of choice and responsibility" (Cohen 1989, 933).

However, in most cases, being worse off because of option luck is different from having directly chosen to be worse off. After all, option luck is a form of luck, even when it arises from deliberate and calculated gambles. Inequalities that reflect option luck may arise from the decisions people have made, but (usually) luck plays a role in determining the outcome of these decisions. ${ }^{4}$ Take, for instance, two equally experienced racegoers who each decide to risk a week's earnings at the racetrack by placing bets on different horses with similar odds. One ends up winning, the other losing. They may be equally responsible for the decision to gamble, but they cannot be considered equally lucky. Both took the same risk and fortune led to a significant gain for one and a significant loss for the other (see also Christiano 1999; Fleurbaey 1998, 213; Lippert-Rasmussen 1999, 482-83). Although the inequality that emerges between them arises from choices they have made, it is still partly a result of luck. Thus, by endorsing the idea of noncompensable option luck, brute luck egalitarians allow inequalities to emerge even if they have not been directly chosen. This sits uneasily with the underlying motivation of luck egalitarianism,

4I say "usually" because the term "option luck" is also used to describe instances where a person has directly chosen an outcome, and where there is consequently no luck involved. See Vallentyne (2002, 534 n. 12). 
which is to achieve a choice and responsibilitysensitive pattern of distribution. ${ }^{5}$

One possible justification for the noncompensable nature of option luck lies is the idea that option luck is deserved, but this does not make sense in situations where two individuals both take risks and end up unequally well-off. For instance, in the example above, does the gambler who wins really deserve greater wealth than the gambler who loses? Both individuals knowingly took a risk, but why does this mean we should ignore the role of luck in generating the inequality between them? Just because a person has chosen to bring luck into play is no reason for her to be entitled to all its fruits. Why should a person enjoy the full benefits of luck when all she has done is place a bet? It seems a strange position for egalitarians to take if they aim to prevent morally arbitrary differences in well-being (Christiano 1999; Lippert-Rasmussen 2001, 571-75).

A second possible justification lies in Dworkin's claim that gamblers have chosen to take a risk and "that the possibility of loss was part of the life they chose" $(2000,74-5)$. But there are problems with this justification when it is applied to cases of inequality between individuals who all take risks, exposing themselves to option luck. Firstly, if individuals end up with different outcomes from the same gamble, they pay different costs for the same choice (as Dworkin recognizes), and this seems unfair from a luck egalitarian point of view. Secondly, the risk takers may pay a cost that is disproportionate to the risk they have taken (Fleurbaey 2001, 511). For instance, a motorcycle rider who is paralyzed in an accident suffers an excessively high cost for choosing to ride a bike (Christiano 1999 and also note Fleurbaey 1995b, 40-1). In these cases, it seems reasonable for the beneficiaries of good option luck to provide assistance to those who suffer excessively bad option luck.

A more convincing argument for noncompensable option luck is that removing inequalities which result from risk taking and gambling will prevent risk takers and gamblers from being able to enjoy the way of life they value. As Dworkin puts it, "[i]f winners were made to share their winnings with losers, then no one would gamble, as individuals, and the kind of life preferred by both those who in the end win and

\footnotetext{
${ }^{5}$ See also Lippert-Rasmussen (2001) for a strong critique of the idea that option luck is noncompensable. My approach in this paper has also been influenced by the excellent analysis of option luck and brute luck in Vallentyne (2002), Otsuka (2002), and Sandbu (2004) who examine different ways of strengthening the conditions that must be in place for outcomes to be considered the result of option luck.
}

those who lose would be unavailable" (2000, 75). Whilst luck egalitarianism does not necessarily provide any reason, in itself, to worry about the diversity of activities available in a society, this criticism becomes more concerning to luck egalitarians if it indicates a failure to respect individual choice (see and compare Lippert-Rasmussen 2001, 552). ${ }^{6}$ Individuals who participate in gambles such as lotteries choose to expose themselves to an activity where the odds of losing are high, for a very small chance of a large win. This is a "gamble proper" because "the gambler prefers facing the gamble to having its expected value" (Lippert-Rasmussen 2001, 555). Thus, to equalize the impact of option luck would undermine the purpose of the gamble by preventing participants from being able to enjoy a small chance of a big win. To provide compensation in such cases would represent a failure to respect the choice each participant has made.

However, as Lippert-Rasmussen (2001, 555) points out, Dworkin classifies gambles as option luck, even if they are "quasi-gambles," rather than gambles proper. In the case of quasi-gambles, the preceding argument against compensable option luck is less convincing because the individuals involved would rather be guaranteed the expected value of the option than face a small chance of a great win. They are motivated by the (likely) prospect of a solid improvement in their financial position, rather than the (unlikely) possibility of a massive pay-off, and provided that sharing out the benefits and burdens of option luck secures a reasonable improvement for each person, those who participate in the gamble would (if asked to choose before they knew the outcome of their own gamble) support such redistribution (see also Fleurbaey 2001, 520-21; Lippert-Rasmussen 2001, 555-56). ${ }^{7}$ To summarize, compensation should be provided in these cases because, firstly, the outcome each individual ends up with is partly the result of luck and, secondly, because each participant would prefer to share out the wins and losses associated with

${ }^{6}$ I say "in itself" because luck egalitarians may value such diversity for reasons that are independent of egalitarian justice (and hence luck egalitarianism). See and compare Dworkin (2000, 75).

${ }^{7}$ The italicized clause is necessary because redistributing the benefits and burdens of option luck could leave all participants worse off, or with such minimal gains that they would prefer to forgo redistribution in order to preserve the chance of a bigger win. In these cases, option luck is noncompensable because of the importance luck egalitarians place on respecting the choices individuals have made. This line of thinking may also explain, in part, why we are drawn to compensate risk takers who are blinded in freakish accidents, but not those who suffer a small loss from participating in lotteries (see and compare Sandbu 2004, 296-99). 
risk taking, thereby avoiding the risk of individual disaster if she is unlucky. The second condition is important because it ensures that providing compensation is consistent with the motivation of the participants' initial decision to gamble. ${ }^{8}$ When these two conditions are met, luck egalitarians should support compensation for option luck inequalities.

In the fourth section, I will explain more precisely how luck egalitarians should calculate the level of redistribution which should occur in these situations. The next section will develop a second major criticism of brute luck egalitarianism, relating to the inegalitarian implications of Dworkin's option-brute distinction. I argue that brute luck egalitarians risk perpetuating existing inequalities if they ignore the way economic and social circumstances shape individual choice. In order to avoid this problem, brute luck egalitarians must adopt an "equal footing proviso" which holds that option luck can only arise in situations where individuals choose on an equal footing. However, I demonstrate in the second section that this leads to a more radically egalitarian notion of individual responsibility than Dworkin is prepared to support. Dworkin's account of the option-brute distinction is sensitive to the impact of material inequalities on individual choice, but the equal footing proviso also demands that brute luck egalitarians take into account the impact of nonmaterial inequalities, including inequalities which influence the process of preference formation. This clashes with Dworkin's long-held view that individuals should be held responsible for their preferences. In the third section, I will examine Cohen's version of brute luck egalitarianism, which is based on the kind of radical notion of responsibility that is required.

\section{Background Inequality and Choice: Dworkin's Approach}

When assessing the egalitarian credentials of the option-brute distinction, it is important to note that

\footnotetext{
${ }^{8}$ The second condition has similarities to Vallentyne's (2002, 549-55) argument that in some situations, individuals may be better off if we share out the gains and losses associated with risk taking. Luck egalitarians should not privilege "the 'natural' option luck payoff structure," so redistribution among risk takers may be appropriate, especially in situations where it is rational to take a risk because doing so maximizes expected utility. LippertRasmussen also uses this argument against Dworkin's (2000, 74) claim that "the price of a safer life... is precisely forgoing any chance of the gains whose prospect induces others to gamble" (2001, 552-54). For further discussion of Vallentyne's position, see Segall (2007, 182-83).
}

Dworkin applies the distinction to a world where a number of egalitarian conditions are already in place. One of the most important is that all individuals have an equal share of social resources-Dworkin is using the option-brute distinction to analyze the inequalities that emerge in a world where everybody starts from an initial position of material equality. This is different from the real world, where individuals start from very unequal positions. Moreover, Dworkin goes on to make a stronger egalitarian assumption, noting "that the argument in favor of allowing differences in option luck to affect income and wealth assumes that everyone has in principle the same gambles available to him" $(2000,76)$. In effect, there are significant egalitarian constraints on the background conditions required for inequalities to be considered the result of option luck. ${ }^{9}$

These conditions are crucial for brute luck egalitarianism to be considered an egalitarian theory, because the kind of lives people live and the decisions they make are likely to be strongly shaped and limited by their upbringing and social environment. ${ }^{10}$ If people start from very unequal positions, then there is a risk that the decisions they make and the lifestyles they lead will perpetuate this inequality. Choices about education, occupation, and investment are likely to be strongly influenced by a person's wealth and income. For instance, a high school graduate from a poor family is likely to find the choice between immediate work and further study more difficult than a similarly talented graduate from a more affluent family. For the poorer family, there is a much greater need for the extra income work would

\footnotetext{
${ }^{9}$ Dworkin believes that the availability of insurance against (some) instances of brute bad luck converts this bad luck into option luck. People have the option of protecting themselves against the risk of brute bad luck with insurance, so choosing not to insure counts as risk-taking behavior that gives rise to option luck. However, this conclusion is also limited by egalitarian conditions. It only holds "if everyone had an equal risk of suffering some catastrophe that would leave him or her handicapped, and everyone knew roughly what the odds were and had ample opportunity to insure." See Dworkin (2000, 73-79, quotation at p. 77).

${ }^{10}$ Phillips (2004, especially pp. 15-19) argues that focusing on luck and choice may lead egalitarians to ignore the links between social structures and inequality. For relevant discussions of background conditions and individual choice see also Barry (2005, viii, 41-42); Callinicos (2000, 56); Mason (2000); Lake (2001); Sypnowich (2003, 341); and Ramsay (2004, especially 29293). More generally, my position here has similarities to the idea that our ability to act prudently may (at least in part) be a matter of luck. For discussion of this idea see Anderson (1999, 300); Arneson (1999, 489, 491); Hurley (2003, 169-71); Parfit (2002, 93); Roemer (1986, 781-82); Scheffler (2005, 13); and Segall (2007, 185-86). I should also note that I take the "background conditions" terminology from Lake (2001, e.g., 83).
} 
bring in, so it will be far more difficult for the individual concerned to take the option of further study. ${ }^{11}$ This is particularly important because the choice involved has significant implications for each graduate's future occupation and income. Another example relates to investment. When there is preexisting material inequality, the wealthy will have a greater opportunity to increase their wealth than other citizens will, as they have more money to invest. But the outcome of an investment seems to be a clear case of option luck, so allowing option luck inequalities to emerge in a world of preexisting material inequality will simply perpetuate this inequality. Dworkin's egalitarian conditions are vital in shoring up the egalitarian credentials of his theory.

In effect, this means that brute luck egalitarianism is only consistent with egalitarian notions of fairness if it is built upon an egalitarian notion of responsibility, which incorporates an equal footing proviso (see also Barry 2006; Christiano 1999; Voigt 2007, 394-96). ${ }^{12}$ For a brute luck egalitarian, individuals can only be held responsible for being worse off or better off than others if they start on an equal footing. The high school graduates in my example are not on an equal footing, so they cannot be held responsible for the level of advantage they enjoy relative to each other. The equal footing proviso ensures that brute luck egalitarianism uses notions of choice and individual responsibility in a way that is consistent with egalitarian notions of fairness. ${ }^{13}$

However, the equal footing proviso leads to a more radically egalitarian notion of responsibility than Dworkin would be prepared to accept. Underlying this proviso is the idea that it is unfair to hold individuals equally responsible for the consequences of decisions taken in unequal circumstances, if these unequal circumstances directly affect the decisionmaking process. But if luck egalitarians wish to

\footnotetext{
${ }^{11}$ A similar example is presented in Barry $(2005,137)$.

${ }^{12}$ I thank an anonymous reviewer of this journal for helping to clarify my thinking on this point, and for suggesting the "equal footing" terminology, which is also used by Arneson (1999, 489). A related argument about choice and background equality is made by Barry (2005, 41-44, 85-89, 136-37), although he is referring to equality of opportunity rather than luck egalitarianism and is critical of the "equality of what debate" (see p. 22). I should also note that the "equal footing" proviso only applies to factors which affect the relative well-being of the individuals we are concerned with. It does not matter if two individuals are unequal in ways that have no bearing on their relative well-being.

${ }^{13}$ Compare Lake (2001) and Hurley (2003, 146-80) who highlight the potential tension between the notion of individual responsibility, and egalitarianism. For related discussion of equality of opportunity and responsibility see also Lippert-Rasmussen (1999).
}

prevent this sort of unfairness, they must extend the equal footing proviso to cover nonmaterial inequalities which influence choices, such as parental attitudes, not simply inequalities in the distribution of income and wealth.

The problem is that social background can have an enormous impact on an individual's beliefs, preferences, and decisions, even against a baseline of material equality (e.g., Mason 2004; Rawls 1971, 74; also note the range of factors identified as sources of disadvantage in Barry 2005, 42, 46). Take, for example, two equally talented students who have recently completed school. With similar marks, both are eligible for the same further educational experiences. However, one comes from a family where a college education is highly valued and the other from a background where it is regarded negatively. Both students have recently attained their majority and meet the requirements of rational agency. Both students choose, with the first deciding to attend college, and the other deciding against it. Ultimately, the college-attendee secures a higher-paid position than the nonattendee because of her higher level of education. This shows that Dworkin must extend the equal footing proviso to nonmaterial inequalities, otherwise, his reliance on individual choice risks perpetuating existing social inequalities relating to class, gender, and ethnicity. ${ }^{14}$

However, Dworkin cannot extend the proviso without abandoning a key plank of his theory. Dworkin holds us responsible for our preferences, even when unchosen factors influence the development of these preferences (e.g., Dworkin 2000, 289-91; 2004, 346-47). ${ }^{15}$ Even if our preferences have been strongly shaped by our social environment, we are obliged to take responsibility for them. This is inconsistent with extending the equal footing proviso to include nonmaterial inequalities which influence our choices because foremost among these are inequalities in factors which influence preference formation. For example, under Dworkin's approach, a person who develops a propensity for participating

\footnotetext{
${ }^{14}$ See Lippert-Rasmussen $(2001,575-79)$ for a related critique of noncompensable option luck.

${ }^{15}$ This is what Vandenbroucke calls a "delegation" view of responsibility because individuals are automatically delegated responsibility (held to be responsible) for their preferences, regardless of the aetiology of these preferences. See Fleurbaey (1998, 208, 225); see also Fleurbaey (1995a, 684) and Vandenbroucke (2001, 11-14). I should also note that Dworkin makes an exception for some preferences, which are more appropriately treated as "handicaps." A preference counts as a "handicap" or "drive" if the person who holds it would rather be without it. See Dworkin (2000, 82-83).
} 
in a dangerous sport such as boxing as a result of his family background will be held responsible for the good/bad (option) luck that arises from his participation in the sport, in violation of the equal footing proviso. This is a troubling conclusion because it means that by respecting individual choice, a purportedly egalitarian theory perpetuates existing nonmaterial inequalities (note also the discussion of preference formation in Macleod 1998, 19-45). ${ }^{16}$ If he is serious about ensuring that individuals choose on an equal footing, Dworkin must revise his views on responsibility for preferences.

However, this would mark a major change in Dworkin's theory. His long-held view is that egalitarians should hold individuals responsible for their tastes, particularly their expensive tastes, regardless of how these tastes were cultivated (see Dworkin 2000, 48-59, 287-99 and Dworkin 2004, 339-50 for discussion of expensive tastes). For Dworkin, this is crucial if we are to incorporate individual choice and responsibility into egalitarian thinking. For instance, a person who has an intense hatred of work (in effect, an expensive distaste) may have been raised in a household where working hard was regarded with contempt. ${ }^{17}$ Dworkin would want to hold this person responsible for this taste, making him pay the costs of his life of leisure (except in the unlikely event that the person considers his aversion to work a handicap). But if he extends the equal footing proviso to cover background inequalities such as parental attitudes, he could no longer classify this man's taste for leisure as option luck, because it largely reflects his upbringing,

\footnotetext{
${ }^{16}$ Dworkin shows greater sensitivity to the issue of preference formation in his later work (Macleod 1998, 42), suggesting that certain conditions may be required for a person's preferences to be considered authentic. Although he does not provide much detail on exactly what this involves, he says that a principle of authenticity has a passive and an active aspect. Individuals should have "both an opportunity to form and reflect on their own convictions, attachments, and projects, and an opportunity to influence the corresponding opinions of others" (Dworkin 2000, 160) and presumably, option luck can only arise from actions that reflect preferences which meet this test of authenticity. However, strengthening the background conditions on option luck in this way is not enough to rescue Dworkin's theory. This account of authenticity demands little more than rational agency in a community with freedom of speech, so the option-brute distinction remains insensitive to the impact of background inequalities. For example, the school graduate in the second example above may well have the opportunity for critical reflection in a society characterized by freedom of speech. But this does not mean that she is exposed to alternative opinions or that she subjects her parents' views to critical scrutiny. For a good discussion of gender socialization and Dworkin's notion of authenticity, see Mason (2000, 240-46).

${ }^{17} \mathrm{~A}$ similar example is used in Arneson $(1999,489)$. Also note Scanlon $(1998,292)$.
}

and Dworkin would be left with the kind of egalitarianism he wishes to avoid.

In this section, I have demonstrated that the option-brute distinction has inegalitarian implications if it is applied to a world where individuals start from unequal positions. To overcome this, brute luck egalitarians must adopt an equal footing proviso, where significant egalitarian conditions regulate the operation of the option-brute distinction and our judgments of responsibility. But this proviso demands that we take into account the impact of nonmaterial background inequalities on preference formation, a conclusion which brute luck egalitarians such as Dworkin are likely to resist. In the next section, I examine whether G.A. Cohen's more nuanced version of brute luck egalitarianism can better handle this problem.

\section{Background Inequality and Genuine Choice: Cohen's Approach}

Although Elizabeth Anderson describes G.A. Cohen as a "luck egalitarian," Cohen has criticized Dworkin's theory of equality of resources, particularly his approach to the issue of responsibility for preferences. Unlike Dworkin, Cohen believes that egalitarians should focus closely on how individuals come to hold particular tastes and preferences when making judgments about whether they should be held responsible for them. Cohen adopts a "control" view of responsibility that seems more consistent with an interpretation of the option-brute distinction that takes into account the impact of nonmaterial background inequalities on individual choice. In this section, I will examine whether Cohen's approach rescues brute luck egalitarianism from the charge of inegalitarianism.

Like Dworkin, Cohen supports the basic impulse of the option luck-brute luck distinction. He argues that:

A person is exploited when unfair advantage is taken of him, and he suffers from (bad) brute luck when his bad luck is not the result of a gamble or risk which he could have avoided. I believe that the primary egalitarian impulse is to extinguish the influence on distribution of both exploitation and brute luck (Cohen 1989, 908).

He explicitly links this to the option-brute distinction (Cohen 1989, 908 n. 3) ${ }^{18}$ and argues that whether an

\footnotetext{
${ }^{18}$ Cohen says: "The latter kind of luck is option luck" (his emphasis; n. 3).
} 
inequality in "advantage" (however this is understood) is legitimate, depends on whether or not an agent can be considered responsible for it (Cohen 1989, 921).

However, Cohen's understanding of responsibility is different from Dworkin's. His view of responsibility is more akin to a control view (Fleurbaey 1998, 227; Vandenbroucke 2001, 12):

I shall... argue that the grounding idea of Dworkin's egalitarianism is that no one should suffer because of bad brute luck and that, since the relevant opposite of an unlucky fate is a fate traceable to its victim's control, my cut is more faithful to Dworkin's grounding idea than the one he ostensibly favors is. (Cohen 1989, 922)

This difference between them is most obvious in the way they handle the issue of responsibility for tastes. Whereas Dworkin holds persons responsible for their tastes and believes that the inequalities that arise from them are legitimate, Cohen believes that compensation for these tastes is sometimes justified. In particular, determining the extent to which a person is responsible for his/her tastes depends on the role he/ she played in forming them, whether he/she could now unform them, and whether he/she endorses them as valuable:

I distinguish among expensive tastes according to whether or not their bearers can reasonably be held responsible for the fact that their tastes are expensive. There are those that they could not have helped forming and/or could not now unform without violating their own judgment, and then there are those for whose cost, by contrast, they can be held responsible, because they could have forestalled their development, and/or because they could now quite readily unlearn them, without violating their own judgment. (Cohen $2004,8)^{19}$

Thus, unlike Dworkin's equality of resources, Cohen's approach will not automatically hold persons responsible for preferences with which they identify.

For Cohen, questions of responsibility hinge on the distinction between genuine choice and brute luck, whilst for Dworkin they hinge on the distinction between preferences and resources (Cohen 1989, 916-34). Under Cohen's approach, a person is responsible for something if it reflects the genuine choices she has made, rather than brute luck. In contrast, Dworkin automatically holds individuals responsible for their preferences, and not their resources. However, Cohen's approach to the question of responsibility is more complex than this suggests.

\footnotetext{
${ }^{19}$ Cohen $(2004,7-8)$ has revised this statement of his position since his earlier work (cf. Cohen 1989, 923).
}

He emphasizes that the whole idea of genuine choice is less clear-cut than some might think:

We are not looking for an absolute distinction between presence and absence of genuine choice. The amount of genuineness that there is in a choice is a matter of degree, and egalitarian redress is indicated to the extent that a disadvantage does not reflect genuine choice. That extent is a function of several things, and there is no aspect of a person's situation which is wholly due to genuine choice (Cohen 1989, 934).

Although he does not provide a detailed outline of the conditions needed for choice to be considered genuine, Cohen has reemphasized and expanded on his approach in his more recent work:

It is false that the only relevant questions about choice and responsibility are whether or not something (an action, a preference) is, simply, chosen (that is, tout court), and that the only relevant upshot is whether the agent is responsible, tout court. Here, as elsewhere, we make judgments of degree of responsibility, and they are based on graded and shaded judgments about choice. It always bears on the matter of responsibility that a person chose a certain course, but it is also always pertinent how genuine that choice was [reference suppressed] and how constraining the circumstances were in which it was made. The genuineness of a choice is a function of the chooser's knowledge, self-possession, and so forth. (Cohen 2004, 21-2)

Thus, the extent to which inequalities will be reduced/ eliminated depends on the extent to which they reflect a person's decisions/actions and on the amount of genuine choice involved in these decisions/actions. This leaves much scope for making the relative judgments about choice that should be central to egalitarianism.

Applied to the option-brute distinction, this presumably means that, for Cohen, pure option luck can only arise from genuine decisions to gamble or take risks. But it is worth noting that this may conflict with Cohen's initial explanation of option luck and brute luck, which focuses on whether a gamble or risk was avoidable (see above). ${ }^{20}$ The reason for this is that a gamble or risk can be fully avoidable without being fully genuine. For instance, background conditions may affect a person's decision to take an avoidable risk. If an individual is offered two jobs, one safe but poorly paid, and the other dangerous but highly paid, he might choose the dangerous one, but only because his parents are impoverished and in

\footnotetext{
${ }^{20}$ For an excellent analysis of the notion of brute luck as unavoidability, see Vallentyne (2002, 532-38). See also Lake (2001, 93-94) for a related discussion of the tension between equality of opportunity and responsibility in Cohen's work.
} 
need of his financial support. The family of his equally risk-averse friend, on the other hand, is well off, and his friend chooses the safer job. In this situation, both individuals can avoid the dangerous job, but the different decisions they make are not equally genuine. ${ }^{21}$ Nonetheless, it is clear that genuineness is Cohen's key concern, ${ }^{22}$ and thus, whether a risk or gamble gives rise to option luck depends, in Cohen's theory, on whether it is genuinely chosen, ${ }^{23}$ not simply whether it is avoidable. ${ }^{24}$

\footnotetext{
${ }^{21}$ The reason one is less genuine than the other is that one person faced greater constraints than the other did in making his choice. The closer an individual gets to ideal circumstances for decision making (with full information, no external constraints, etc), the closer he gets to making a fully genuine decision. If background inequalities mean that some persons are closer to these ideal circumstances than others are, then the choices they make can be considered more genuine. It is for this reason that relativities affect the genuineness of a choice.
}

${ }^{22}$ I would like to thank two anonymous reviewers for emphasizing this point.

${ }^{23}$ It is also important to remember that the genuineness of a choice, for Cohen, is a matter of degree. He links this idea to Dworkin's claim that option luck and brute luck sit on a continuum (Cohen 1989, 934 n. 62), and he says that "egalitarian redress is indicated to the extent that a disadvantage does not reflect genuine choice" (934). Presumably this means that an outcome reflects option luck in proportion to the amount of genuineness involved in the decision to take a risk. Thus, if someone's decision to take a risk is only half-genuine, then half of the outcome of the risk is the result of option luck and hence noncompensable, whilst the other half is the result of brute luck and hence compensable. This is also the implication of Dworkin's initial claim that "the difference between these two forms of luck [i.e. option luck and brute luck-NB] can be represented as a matter of degree" (2000, 73). However, Dworkin's subsequent use of the option-brute distinction does not seem consistent with this initial claim. Insurance, for example, creates "a link between brute and option luck" (74), but Dworkin holds that those who suffer an accident after failing to take out insurance are not entitled to any compensation on the grounds of egalitarian justice (76-77). Admittedly, Dworkin later retreats from this conclusion, but this is because certain conditions, outlined in note 9 above, are not satisfied in the real world (see 77-79), not because option luck is a matter of degree.

${ }^{24}$ Instead of focusing on the genuineness of choices, another possibility is to define option luck in terms of risk taking that was reasonably avoidable, so option luck can only arise when an individual faced and rejected reasonable alternatives to the option she took. However, this does not solve the problem, because the idea of reasonable avoidability may also be insensitive to the impact of background inequalities. In the first high school graduate example above (see the second section), it is not necessarily unreasonable to expect the graduate to sacrifice her family's short-term financial position for the sake of her future career, as this will probably allow her to better support her family in the long-term. An individual may take a risk that is reasonably avoidable without being fully genuine. For work on the role a notion of reasonableness might play in distinguishing option luck and brute luck see Ripstein (1999, 264-295); Lippert-Rasmussen (2001, 574); Otsuka (2002); Stemplowska (2002); Vallentyne (2002); Sandbu (2004); and Voigt (2007, 396-99). See also Macleod (1998, especially 73-76).
This version of brute luck egalitarianism is sensitive to the impact of background inequalities on decision making, providing an egalitarian way to regulate the use of choice in distributive justice, ensuring that luck egalitarianism does not simply perpetuate existing inequalities, and thus refuting a major criticism of the theory. ${ }^{25}$ Nonetheless, given the demanding conditions set by the equal footing proviso, the term "option luck" may no longer be an appropriate one to use. The term implies that individuals are responsible for the outcomes of whatever options they choose, and this seems to obscure the way background conditions shape individual choices. In reality, luck egalitarians, particularly Cohen, have a more sophisticated understanding of choice and option luck than this suggests, but in order to avoid confusion, luck egalitarians may do well to refer directly to "genuine choice" and "genuinely chosen gambles" instead of option luck. ${ }^{26}$

But terminology aside, a more significant problem remains. Although Cohen's form of brute luck egalitarianism is sensitive to the impact of background inequalities on individual choice, addressing the problem I highlighted in the second section, it cannot solve the problem of noncompensable option luck that I highlighted in the first section. Brute luck egalitarianism, even in this revised form, would still hold individuals fully responsible for the outcome of fully genuine risk taking, and as I argued above, this is unfair. ${ }^{27}$ As I will explain in the next section, we should not focus simply on whether we are responsible for our choices but rather on the extent to which we should be held responsible for the outcomes of these choices, where "outcomes" means the impact of these choices on our level of well-being (see also Sandbu 2004, 292). Once we have made this move, there is no longer any reason to distinguish between different kinds of luck, and thus there is no need to preserve the option-brute distinction. In the next section, I will outline a revised version of luck

\footnotetext{
${ }^{25}$ Other theorists also recognize that luck egalitarianism can take into account the way luck-derived factors affect individual choices. See, for example, Arneson (1989; 1999, 488-89, 496); Callinicos (2000, 65); Knight (2006, 181-82); and Voigt (2007).

${ }^{26}$ In fact, this is the approach Cohen tends to adopt in his own work, where he rarely uses the term "option luck."

${ }^{27}$ Even if fully genuine choice rarely/never occurs, brute luck egalitarians will still hold individuals partially responsible for the outcome of partially genuine risk taking, in proportion to the degree of genuineness involved in the decision to take a risk. As I will argue below, risk takers may be entitled to further compensation for the role luck plays in determining the outcome of the risky option (once it has been chosen), not just for the impact of luck-derived factors on their decision to choose this option.
} 
egalitarianism that is based on this idea and that avoids the criticisms advanced in the first three sections.

\section{Towards a Revised Theory of Luck Egalitarianism}

Instead of the option luck-brute luck distinction, luck egalitarians should focus on the extent to which people can be considered to have chosen their current level of well-being, and the extent to which this choice is genuine, as opposed to a reflection of background constraints and preexisting inequalities. To the extent that a person's level of well-being has not been chosen, and to the extent that a relevant choice is not genuine, it can be considered a matter of luck. According to luck egalitarianism, we should equalize the extent to which luck affects the lives of individuals. ${ }^{28}$ This means that those who enjoy good luck are obliged to share its benefits with their fellow citizens and that the victims of bad luck are entitled to compensation from those with better luck. Individuals will only be unequally well-off if it is justified by differential individual choice, and the equal footing proviso is satisfied.

This version of luck egalitarianism avoids the problem of noncompensable option luck because it does not regard differential option luck as inherently just - the victims of bad option luck may be entitled to a share of the advantages enjoyed by the beneficiaries of good option luck. The revised version also avoids the problem discussed in the second section because it is sensitive to the impact of background inequalities on choice. By adopting Cohen's focus on the genuineness of choices, it is equipped to make the nuanced judgments required of an egalitarian theory.

But how do we determine the extent to which a person's level of well-being is the result of luck, as

\footnotetext{
${ }^{28}$ I say equalize, rather than neutralize, because we are interested in the luck individuals enjoy, relative to each other. For instance, if I make a bad decision because of my background then this is a case of bad luck. If everyone else chose better (because of their backgrounds), then they have enjoyed better luck than me, and this is unjust from a luck egalitarian point of view. On the other hand, if everyone else made the same bad choice as me because of some similarity in our upbringing and we all end up equally badly off, I still suffer from bad luck, but so does everyone else, and for this reason, there is no injustice involved. Of course, most luck egalitarians would agree that, for other reasons, it would have been better if people had chosen more prudently, but luck has had an equal impact on each individual, and as long as our key concern is egalitarian justice, this is what matters. See also Cohen $(2004,14-15)$.
}

opposed to genuine choice? To answer this question, we must focus on the different ways in which luck can affect us. Firstly, our lives can be improved/ worsened by unchosen factors, such as inherited wealth and hereditary illness, and because our exposure to these factors is unchosen, their impact on our well-being is entirely the result of luck (which brute luck egalitarians would classify as brute luck). Thus, if some individuals are better off than others purely because of these unchosen factors, the inequality that results is luck derived, and fully compensable.

Luck also plays a role when unchosen background conditions affect the choices we make. The most obvious example is when luck shapes the set of options we face. If one person ends up better off than others because she had better options to choose from (purely as a result of luck), then this inequality is luck derived and fully compensable. Luck-derived background conditions may also affect the genuineness of a person's choice by limiting her ability to take up certain options. ${ }^{29}$ For instance, in the first school graduate example discussed above, one student finds it difficult to choose the option of college attendance because of her family's financial position. If she ends up with a lower level of well-being as a result of her nonattendance (because she is forced to work in a low-paid job which, let us assume, has an adverse impact on her level of well-being), then the impact of this nongenuine choice is considered to be the result of luck. The other school graduate in this example is from a richer family and, free of the financial pressures facing the poorer student, she decides to attend college. If these two individuals end up with an unequal level of well-being, purely because of the different decisions they made regarding college attendance, then this inequality is luck derived and fully compensable.

It is also possible that people will be ignorant of the full range of options available to them or that they will misunderstand the likely consequences of these options. This is one reason luck egalitarians should focus on the extent to which outcomes are genuinely chosen-individuals may genuinely choose particular options, without a full understanding of their consequences. In such cases, the options are

\footnotetext{
${ }^{29}$ Arneson (e.g., 1989, 1999) also recognizes that this issue is relevant to egalitarian judgments, although I am not suggesting that he would endorse the approach outlined here. I should also note that in assessing how difficult it is for an individual to choose a particular option we must take into account any associated welfare costs. To return to the example discussed above, an individual may, as a result of her parents' attitudes, end up with an extreme aversion to work that makes it costly (in welfare terms) for her to choose to work.
} 
genuinely chosen, but the outcomes of these options are not. In the second school graduate example for instance (see the second section), one individual has a more accurate perception of the advantages of college education than the other because of differences in their upbringing. This means that one student makes a more genuine choice of outcome than the other does, and the inequality that results between them is luck derived and fully compensable (Cohen 1989, 934 makes a similar point about the link between access to information and the genuineness of choices; see also Lippert-Rasmussen 2001, 566-67; Barry 2005, 137). ${ }^{30}$

The final way luck influences well-being is by determining the outcome of a genuine decision to take a risk. The risk taker does not know what the outcome will be, although she knows the possible consequences of her decision and the odds involved. In such cases, how do we determine the extent to which the risk taker has genuinely chosen the end

\footnotetext{
${ }^{30}$ It is worth briefly noting how the revised version of luck egalitarianism proposed here handles the problem of cheap adaptive preferences. This is best illustrated by the "tamed housewife" example. As Roemer explains it, " $[t]$ he tamed housewife is one who, owing to the apparent impossibility of surviving outside a highly restricting marriage, adopts preferences in which she likes cleaning house, changing diapers, washing dishes, and the like" $(1998,20)$. In other words, her preferences adapt to her circumstances, so she ends up with an average level of subjective welfare, although her situation seems worse (in an objective sense) than everyone else's. In determining how the revised version of luck egalitarianism handles this example, we must first consider whether it classifies the tamed housewife as disadvantaged, despite her subjective welfare level. This will depend on the conception of advantage/well-being that we adopt, and I have said little about this throughout the paper, referring simply to the well-being of individuals, without precisely explaining what this means (although my use of the term "well-being" suggests that I am interested in something more than simply the resources a person holds). There is no space here for a full account of egalitarian advantage, but my view is that objective factors (amongst other considerations) are relevant to judgments of individual well-being (see N. Barry 2006 and also note Callinicos 2000, 60-64; Sypnowich 2003), and thus, in at least one respect, I consider the tamed housewife to be disadvantaged.

The second issue is whether the tamed housewife has genuinely chosen the outcome she ends up with (i.e., the objective disadvantage she suffers). Although the tamed housewife comes to endorse the life she lives, it would be a mistake to regard it as genuinely chosen. Without any viable alternatives, the tamed housewife is effectively forced into marriage, and for this reason, we cannot consider her disadvantaged position to be genuinely chosen. This conclusion does not rest on the assumption that the tamed housewife is suffering from false consciousness, but rather, it arises because she faced such a poor range of options. If the situation were different and she faced a better array of options, had a full understanding of the consequences of each option, and could freely and costlessly have chosen any one of them, then her choice to opt for marriage and domesticity would be considered genuine. I would like to thank an anonymous reviewer for highlighting the importance of addressing this issue.
}

result? For a start, it is important to emphasize that luck determines the outcome, so it can only be considered "chosen" in a technical sense. What this terminology aims to capture is that we are interested in the extent to which the actual outcome was a likely and foreseeable consequence of the option selected.

To begin with, consider cases where all individuals start on an equal footing and make a genuine decision to take a risk. That is, they face the same options, have perfect information, and are unaffected by any other background inequalities (including nonmaterial background inequalities which have affected the formation of their preferences). In this situation, all the risk takers have elected to take a chance, and consequently, the outcome that each ends up with will, at least in part, reflect luck rather than choice. I say "in part" because individuals may select options that involve a greater/lesser degree of risk, and in such cases, it would be inappropriate to ascribe the outcome completely to the effects of luck (see also Lippert-Rasmussen 2001, 558-59; Vallentyne 2002, 535-36). In these cases of risk taking in conditions of background equality, luck egalitarians should measure the impact of luck on a person's life with reference to the divergence between the expected value of the option she selects, and the actual outcome. ${ }^{31}$ If the divergence is in a positive direction (the value of the actual outcome exceeds the expected value), then she has benefited from good luck. If the divergence is in a negative direction (the value of the actual outcome is less than the expected value), she has suffered from bad luck. ${ }^{32}$ To apply luck egalitarianism, we must calculate the impact of luck on each risk taker and act to ensure that the benefits and burdens associated with this luck are shared equally amongst them all.

For instance, person A chooses option 1, which has an expected value of 5,000 units. Person B, on the other hand, chooses option 2, which has an expected value of 4,000 units, but may lead to a greater windfall than is possible under option 2. If A ends up with 10,000 units, and B ends up with nothing, then A enjoys 5,000 units worth of good luck, whilst B suffers 4,000 units worth of bad luck. According to

\footnotetext{
${ }^{31}$ In essence, this is the approach taken by Goodin $(1985,584-85)$ in his analysis of desert claims and uncertain outcomes. Also note Sandbu (2004, 297-99), who argues that the expected value of an option influences brute-luck-egalitarian judgments regarding compensation for risk taking; see Fleurbaey (2001, 521); see and compare Voigt (2007, 392-3).

${ }^{32}$ I should emphasize again that I am an interested in the impact of luck on a person's level of well-being. Thus, the outcome and expected value are measured in units of whatever conception of well-being we decide to adopt.
} 
the redistributive scheme outlined above, half of A's 5,000 units worth of good luck goes to B who now has 2500 units, leaving A with 7,500 units. The next step is to share out the cost of B's 4,000 units worth of bad luck by taking 2,000 units from $A$ and giving it to $B$. This leaves A with 5,500 units and B with 4,500 units. There is still a gap between A and B because B chose a riskier option than $\mathrm{A}$, but we have now equalized the impact of luck on their lives. This approach solves the difficult issue of redistribution amongst those who take gambles in conditions of equality.

Nonetheless, we must remember that this redistributive scheme is limited by condition 2 (see section 1 above). Condition 2 holds that redistribution should only occur when risk takers would prefer to share out the wins and losses associated with risk taking (via this redistributive scheme), than to let luck run its course (which means leaving each risk taker to bear the outcome of her "gamble"). Whilst fully assessing the impact of condition 2 is beyond the scope of this paper, it is likely to reduce significantly the number of cases in which luck egalitarianism supports correcting the outcomes of gambles. However, we can note that, at the very least, redistribution will occur in cases where individuals take small risks, motivated by the desire to moderately improve their position. For example, individuals who make "safe" investments in reliable shares are aiming to achieve a steady improvement in their financial position, and equalizing the impact (on their respective financial positions) of the luck that has affected their investments is unlikely to prevent them from achieving this goal. We do not violate their choices by applying the redistributive scheme, so condition 2 is satisfied. This highlights the radical nature of luck egalitarianismit may require redistribution even in cases where individuals on an equal footing freely choose to take risks.

However, we must also consider an important variation to the case just described. Some individuals may choose to play it safe, choosing risk-free options where they know what the outcome will be. In such cases, condition 1 (see the first section) also comes into play: redistribution is only appropriate if the outcome each individual enjoys is luck affected. Assuming that all risk takers and nonrisk takers have made genuine choices, this means that redistribution should only occur amongst those who have chosen to take a risk, because only they end up with luckaffected outcomes. Individuals who decide to play it safe, selecting a risk-free option, directly choose the outcome they end up with (it is not affected by luck), so the first condition remains unsatisfied. They should not share in the benefits or burdens associated with risk taking because any inequality that emerges between risk takers and nonrisk takers is rooted in the different initial choice they made about whether to expose themselves to the vagaries of fortune, which means that it would be inappropriate to consider the inequality luck derived (see also Dworkin 2000, 74). ${ }^{33}$

But although this demonstrates, at the theoretical level, how luck egalitarians should determine the extent to which luck has influenced the well-being of individuals and the amount of redistribution which should occur, in order to apply the theory in practice, we would need to have more detailed information about the decisions people have made, the expected value of the options they confronted, their natural capacities, family background, etc., and in practice, we are unlikely to have this information (see also Fleurbaey 2001, 516). Even if it were possible for the state to gather this data, it could only do so through mechanisms which would violate important values such as individual privacy (see Anderson 1999; Wolff 1998). In the face of these difficulties, we may be tempted to reject luck egalitarianism as a fatally flawed interpretation of egalitarian justice. However, this would be too hasty. My aim in this paper is to establish a more precise understanding of egalitarian justice on an abstract level, leaving aside questions of implementation, and competing values such as individual privacy. In assessing the merits of the different theories on offer, I am concerned with factinsensitive normative principles, not regulative principles that are designed to take practical limitations into account (see Cohen 2003, 244-45). Luck egalitarianism is a theory of egalitarian justice, not an exhaustive guide to political morality or public policy.

Nonetheless, it is still possible to draw conclusions about the likely practical applications of luck egalitarianism. Unable to gather the detailed information we need to implement a pure form of the theory, we are forced to rely on general judgments about the extent to which real-world inequalities reflect the differential impact of luck, rather than

\footnotetext{
${ }^{33}$ In its handling of option luck, the revised version of luck egalitarianism outlined here has similarities to another approach identified in the literature, which Arneson (1999, 490-91) terms "strict equality of opportunity." However, the theory I have outlined differs from this approach because condition 2 regulates whether compensation is provided to those who genuinely elect to take risks. In other words, the outcomes of risk taking will not always be equalized amongst risk takers. Vallentyne's notion of "equality of luck" (2002, 539-40), and Segall's notion of "option luck egalitarianism" are similar to "strict equality of opportunity" (2007, 179-82).
} 
the different choices individuals have made. For instance, luck clearly plays a major role in determining an individual's income. One reason for this is that an individual's luck-derived natural talents affect the kind of job she is able to obtain. Another reason is that differences in family background, such as parental attitudes towards education, also have a big impact on a child's educational performance, and this is a matter of luck. More generally, the occupation and income level of one's parents seem to have a strong bearing on one's own occupation and income. Imagine, for instance, how many doctors and lawyers are the children of doctors and lawyers, as opposed to miners or factory workers. This claim is also supported by recent empirical research which highlights the limited nature of intergenerational economic mobility in America (Bowles, Gintis, and Groves 2005). Mazumder (2005) estimates that the level of intergenerational elasticity in earnings in the United States is 0.62 , which indicates that there is actually less mobility than previously thought. ${ }^{34}$ Moreover, he presents data which shows that amongst "sons whose fathers were in the bottom [earnings] decile, $50 \%$ will have earnings below the $30^{\text {th }}$ percentile and $80 \%$ will have earnings below the $60^{\text {th }}$ percentile. More than $50 \%$ of the offspring of fathers in the top decile will have earnings above the $80^{\text {th }}$ percentile and $68 \%$ will have earnings above the median" (Mazumder 2005, 92). At either end of the earnings spectrum, a man has a high chance of ending up with similar earnings to his father. Of course, this does not demonstrate that earnings in the United States entirely reflect the impact of luck, but it does suggest that background inequalities have an enormous impact on future earnings.

We reach a similar conclusion in relation to wealth. For a start, luck will play a role because as we have seen, a person's income is shaped by luck, and higher income earners will have more income to save and invest than others (see also Van Parijs 1995, 119). Luck will also play a role in determining how successful investments are. But the most obvious luck-derived cause of inequality in the distribution of wealth is inheritance. For this reason alone, wealth inequalities are greatly shaped by luck (see also Barry 2005, 189).

Once we recognize the extent to which inequalities in income and wealth tend to reflect the impact of luck, rather than the different choices individuals

\footnotetext{
${ }^{34}$ To put this in perspective, a figure of 1 would indicate a very rigid society, whilst 0 would indicate a very high level of mobility, where there is generally no connection between father-son earnings. See Mazumder (2005, 83-84).
}

have made, we get a sense of the radical implications of luck egalitarianism. The effects of luck are so pervasive that, if we are unable to make judgments about individuals on a case-by-case basis, we should adopt a general presumption in favor of equality of outcome. Absent more detailed information, we should assume that any inequalities in income and wealth are the result of luck rather than genuine individual choice. ${ }^{35}$ This may produce some injustice, redistributing resources towards those who are responsible for being worse off than others, but the pervasive nature of luck means that this is the most reliable second-best strategy for implementing the theory. ${ }^{36}$

But if the best approximation of luck egalitarianism is equality of outcome, why not simply abandon luck egalitarianism in favor of this more straightforward notion of equality? In response to this, I would emphasize, firstly, that luck egalitarianism and equality of outcome differ at the theoretical level. As long as we value analytical precision, we must avoid conflating the two approaches. Secondly, there are pragmatic reasons to recognize luck egalitarianism as a distinct theoretical position. As I noted above, notions of individual choice and responsibility play an important role in contemporary politics, and one of the great advantages of the luck egalitarian project is that it highlights the radical redistributive consequences of taking these ideas seriously (see Barry 2006).

Nonetheless, egalitarian justice is not the only value of concern to policy makers, and thus, although equality of outcome is a useful second-best strategy for applying luck egalitarianism to the real world in the face of severe informational constraints, policy makers may need to make further compromises in order to avoid adverse outcomes. For instance, a familiar objection to radical egalitarianism is that it distorts the market and leads to economic disaster. If this criticism is correct, policy makers would need to retreat from the radical redistribution of income and wealth outlined above. However, if such changes are

\footnotetext{
${ }^{35}$ Ramsay (2003) and Barry (2005) make similar arguments about the radical implications of luck egalitarianism and related approaches and contrast this to the kind of policies that politicians try to justify in the name of individual responsibility. But whereas they are both critical of the luck egalitarian project, I continue to defend it. There is no need for luck egalitarians to be embarrassed about the radical implications of the theory they support. See also Macleod (1998, 117-18, 150-55); Callinicos (2000); Otsuka (2002); Barry (2006); also note Phillips (2004).

${ }^{36}$ Of course, if information becomes available which allows us to make more precise judgments in particular cases, we can depart from the default position of outcome equality.
} 
necessary, it is important to recognize that they are compromises. As I argued above, we are interested in the best interpretation of the value of egalitarian justice. We are not looking for a complete theory of political morality, or an exhaustive guide to public policy, so the fact that compromises are necessary in the name of other values, or because of practical limitations does not, in itself, indicate that the theory of luck egalitarianism is flawed. Shifting notions of choice and responsibility to the center of egalitarian thinking has radical implications for the distribution of social resources, even if nonegalitarian considerations force departures from this radicalism.

\section{Conclusion}

In this paper, I have outlined a revised version of luck egalitarianism that focuses on the extent to which each person can be considered to have chosen her level of well-being, and the extent to which this choice is genuine, as opposed to a reflection of background conditions and preexisting inequalities. This approach escapes the objection highlighted in the first section by providing compensation for some instances of option luck inequality, and it avoids the inegalitarianism highlighted in the second section by focusing on the genuineness of choices. Thus, having rejected the distinction between compensable brute luck and noncompensable option luck, we can build a theory of equality that incorporates choice in a truly fair and egalitarian way.

My argument in this paper has a number of broader implications. Firstly, it suggests that one of the major criticisms of luck egalitarianism is misplaced. Critics (e.g., Anderson 1999; Fleurbaey 1995b; Scheffler 2003) have attacked luck egalitarianism on the grounds that it is too harsh, denying compensation to those who are responsible for being badly off. However, the theory I have outlined here incorporates strict conditions which regulate when a person can be considered genuinely responsible for her level of well-being. Thus, even if it were possible to implement a "pure" form of the theory, instances of harsh treatment would rarely arise (also note Barry 2006; Christiano 1999; see and compare Voigt 2007). This conclusion is strengthened because the revised version of luck egalitarianism may support redistribution between successful and unsuccessful risk takers. Of course, as I explained, this depends on the expected values of the risks taken, and on whether providing compensation would violate condition 2 , but it will further reduce the scope of the harshness objection (see and compare Vallentyne 2002, 556). Moreover, in cases where no compensation is provided, the fact the theory is sensitive to the impact of background inequalities on individual choices reduces the force of the objection. If someone has genuinely chosen to engage in an activity that she knows is highly risky, and if providing her with compensation would violate the choice she has made, it seems difficult to argue on the grounds of egalitarian justice, as opposed to other values such as compassion or benevolence, that we have an obligation to assist her if she is injured.

Secondly, critics (e.g., Anderson 1999) have attacked luck egalitarianism on the grounds that it requires intrusive state intervention in the lives of individuals. However, I have argued that this criticism relates to the practical application of luck egalitarianism and that it does not highlight any underlying theoretical flaw (see also Cohen 2003). Confronted by the limitations of practical feasibility and the need to respect individual privacy, the safest strategy for luck egalitarian policy makers is to adopt a presumption in favor of equality of outcome (see and compare Vallentyne 2002, 556). It is also interesting to note that the differences between luck egalitarianism and more conventional understandings of equality diminish once we take into account the sorts of practical considerations from which luck egalitarians abstract (also note Scanlon 2006).

Finally, my argument has mixed implications for politicians who are committed to the project of liberal and social democratic policy modernization. Whilst the revised version of luck egalitarianism I have outlined provides a way of linking left-liberal political theory to the popular notion of individual responsibility, its radical redistributive implications run counter to the recent direction of this policy modernization (note Barry 2005; Ramsay 2004, 295-96). Thus, whilst liberal and social democratic modernization may be justified by considerations of economic efficiency and political expediency, its ultimate normative grounding is not the marriage of egalitarian justice and individual responsibility.

\section{Acknowledgments}

An earlier version of this paper was presented at the 2004 UK Association for Legal and Social Philosophy conference in Newport, Wales. I would like to thank conference participants for their comments and UWA's Graduate Research School for a conference travel grant. I would also like to thank Richard 
Arneson, Alex Coram, Colin Macleod, Shlomi Segall, and three anonymous reviewers for their comments. I am especially grateful to David van Mill for his criticisms of a number of drafts.

\section{Manuscript submitted 23 September 2005 \\ Manuscript accepted for publication 6 April 2007}

\section{References}

Anderson, Elizabeth S. 1999. "What is the Point of Equality?" Ethics 109 (2): 287-337.

Arneson, Richard J. 1989. "Equality and Equal Opportunity for Welfare.” Philosophical Studies 56 (2): 77-93.

Arneson, Richard J. 1999. "Equality of Opportunity for Welfare Defended and Recanted." The Journal of Political Philosophy 7 (4): 488-97.

Arneson, Richard J. 2000. "Luck Egalitarianism and Prioritarianism." Ethics 110 (2): 339-49.

Barry, Brian. 2005. Why Social Justice Matters. Cambridge: Polity.

Barry, Nicholas. 2006. "Defending Luck Egalitarianism." Journal of Applied Philosophy 23 (1): 89-107.

Bowles, Samuel, Herbert Gintis, Melissa Osborne Groves (eds.) 2005. Unequal Chances: Family Background and Economic Success. Princeton: Princeton University Press.

Callinicos, Alex. 2000. Equality. Cambridge: Polity.

Christiano, Thomas. 1999. "Christiano Reviews Anderson." Brown Electronic Article Review Service, http://www.brown.edu/ Departments/Philosophy/bears/9904chri.html (November 14, 2003)

Cohen, G.A. 1989. "On the Currency of Egalitarian Justice." Ethics 99 (4): 906-44.

Cohen, G.A. 2003. "Facts and Principles." Philosophy and Public Affairs 31 (3): 207-45.

Cohen, G.A. 2004. “Expensive Taste Rides Again.” In Dworkin and His Critics, ed. Justine Burley. Malden: Blackwell Publishing, 3-29.

Dworkin, Ronald. 2000. Sovereign Virtue: The Theory and Practice of Equality. Cambridge and London: Harvard University Press.

Dworkin, Ronald. 2002. "Sovereign Virtue Revisited." Ethics 113 (1): 106-43.

Dworkin Ronald. 2003. "Equality, Luck and Hierarchy." Philosophy and Public Affairs 31 (2): 190-98.

Dworkin, Ronald. 2004. "Ronald Dworkin Replies." In Dworkin and His Critics, ed. Justine Burley. Malden: Blackwell Publishing, 339-95.

Fleurbaey, Marc. 1995a. "Equality and Responsibility." European Economic Review 39: 683-89.

Fleurbaey, Marc. 1995b. "Equal Opportunity or Equal Social Outcome." Economics and Philosophy 11: 25-55.

Fleurbaey, Marc. 1998. "Equality among Responsible Individuals." In Freedom in Economics, ed. J.F. Laslier, M. Fleurbaey, N. Gravel, and A. Trannoy. London: Routledge, 206-34.

Fleurbaey, Marc. 2001. "Egalitarian Opportunities." Law and Philosophy 20 (5): 499-530.
Goodin, Robert. 1985. "Negating Positive Desert Claims." Political Theory 13 (4): 575-98.

Hurley, Susan. 2003. Justice, Luck and Knowledge. Cambridge, MA and London: Harvard University Press.

Kaufman, Alexander. 2004. "Choice, Responsibility and Equality." Political Studies 52 (4): 819-36.

Knight, Carl. 2005. "In Defence of Luck Egalitarianism." Res Publica 11 (1): 55-73.

Knight, Carl. 2006. "The Metaphysical Case for Luck Egalitarianism." Social Theory and Practice 32 (2): 173-89.

Lake, Christopher. 2001. Equality and Responsibility. Oxford: Oxford University Press.

Lippert-Rasmussen, Kasper. 1999. "Arneson on Equality of Opportunity for Welfare." The Journal of Political Philosophy 7 (4): 478-87.

Lippert-Rasmussen, Kasper. 2001. "Egalitarianism, Option Luck, and Responsibility." Ethics 111 (3): 548-79.

Macleod, Colin M. 1998. Liberalism, Justice, and Markets: A Critique of Liberal Equality. Oxford: Clarendon Press.

Mason, Andrew. 2000. "Equality, Personal Responsibility, and Gender Socialisation." Proceedings of the Aristotelian Society 100 (3): 227-46.

Mason, Andrew. 2004. "Equality of Opportunity and Differences in Social Circumstances." The Philosophical Quarterly 54: 368-88.

Mazumder, Bhashkar. 2005. "The Apple Falls Even Closer to the Tree Than We Thought: New and Revised Estimates of the Intergenerational Inheritance of Earnings." In Unequal Chances: Family Background and Economic Success, ed. Samuel Bowles, Herbert Gintis, Melissa Osborne Groves. Princeton: Princeton University Press, 80-99.

Otsuka, Michael. 2002. "Luck, Insurance and, and Equality." Ethics 113 (1): 40-54.

Parfit, Derek. 2002. "Equality or Priority?" In The Ideal of Equality, ed. Matthew Clayton and Andrew Williams. Houndmills: Palgrave Macmillan, 81-125.

Phillips, Anne. 2004. "Defending Equality of Outcome." The Journal of Political Philosophy 12 (1): 1-19.

Ramsay, Maureen. 2004. "Equality and Responsibility." Imprints 7 (3): 269-96.

Rawls, John. 1971. A Theory of Justice. London: Oxford University Press.

Ripstein, Arthur. 1999. Equality, Responsibility and the Law. Cambridge: Cambridge University Press.

Roemer, John. 1986. "Equality of Resources Implies Equality of Welfare." Quarterly Journal of Economics 101 (4): 751-84.

Sandbu, Martin E. 2004. “On Dworkin's Brute-Luck-OptionLuck Distinction and the Consistency of Brute-Luck Egalitarianism." Politics, Philosophy \& Economics 3 (3): 283-312.

Scanlon, Thomas. 1998. What We Owe to Each Other. Cambridge: Harvard University Press.

Scanlon, Thomas. 2006. "Justice, Responsibility, and the Demands of Equality." In The Egalitarian Conscience: Essays in Honour of G.A. Cohen, ed. Christine Sypnowich. New York: Oxford University Press, 70-87.

Scheffler, Samuel. 2001. "Responsibility, Reactive Attitudes, and Liberalism in Philosophy and Politics." In Boundaries and Allegiances: Problems of Justice and Responsibility in Liberal Thought. New York: Oxford University Press, 12-31.

Scheffler, Samuel. 2003a. "What is Egalitarianism?" Philosophy and Public Affairs 31 (1): 5-39. 
Scheffler, Samuel. 2003b. "Equality as the Virtue of Sovereigns: A Reply to Ronald Dworkin." Philosophy and Public Affairs 31 (2): 199-206.

Scheffler, Samuel. 2005. "Choice, Circumstance, and the Value of Equality.” Politics, Philosophy \& Economics 4 (1): 5-28.

Segall, Shlomi. 2005. "Unconditional Welfare Benefits and the Principle of Reciprocity." Politics, Philosophy \& Economics 4: 331-54.

Segall, Shlomi. 2007. "In Solidarity with the Imprudent: A Defense of Luck Egalitarianism." Social Theory and Practice 33 (2): 177-98.

Stemplowska, Zofia. 2002. "The Concept of Luck in Contemporary Theories of Egalitarian Justice." M.Phil thesis. Oxford University.

Sypnowich, Christine. 2003. "Equality: From Marxism to Liberalism (and Back Again)." Political Studies 1 (3): 333-43.

Vallentyne, Peter. 2002. "Brute Luck, Option Luck and Equality of Initial Opportunities.” Ethics 112 (3): 529-57.
Vandenbrouke, Frank. 2001. Social Justice and Individual Ethics in an Open Society: Equality, Responsibility, and Incentives. Berlin: Springer.

Van Parijs, Philippe. 1995. Real Freedom for All: What (if anything) can justify capitalism? Oxford: Clarendon Press.

Voigt, Kristin. 2007. “The Harshness Objection: Is Luck Egalitarianism Too Harsh on the Victims of Option Luck?" Ethical Theory and Moral Practice 10 (4): 389-407. http://www. springerlink.com/content/k70mv467v2820778/fulltext.pdf (July 22, 2007). Forthcoming.

Wolff, Jonathan. 1998. "Fairness, Respect, and the Egalitarian Ethos." Philosophy and Public Affairs 27 (2): 97-122.

Nicholas Barry is a research fellow of political science and international relations, The University of Western Australia, Perth, WA 6009. 